\title{
Au corps du texte. Hommage à Georges Molinié. Sous la direction de Delphine Denis, Mireille Huchon, Anna Jaubert, Michael Rinn et Olivier Soutet
}

\section{Monica Pavesio}

\section{(2) OpenEdition Journals \\ Edizione digitale \\ URL: https://journals.openedition.org/studifrancesi/4672 \\ DOI: $10.4000 /$ studifrancesi.4672 \\ ISSN: 2421-5856 \\ Editore \\ Rosenberg \& Sellier \\ Edizione cartacea \\ Data di pubblicazione: 1 avril 2012 \\ Paginazione: 143 \\ ISSN: 0039-2944 \\ Notizia bibliografica digitale \\ Monica Pavesio, «Au corps du texte. Hommage à Georges Molinié. Sous la direction de Delphine Denis, Mireille Huchon, Anna Jaubert, Michael Rinn et Olivier Soutet», Studi Francesi [Online], 166 (I | LVI) | \\ 2012, online dal 30 novembre 2015, consultato il 19 novembre 2021. URL: http:// \\ journals.openedition.org/studifrancesi/4672 ; DOI: https://doi.org/10.4000/studifrancesi.4672}

Questo documento è stato generato automaticamente il 19 novembre 2021.

\section{cc) (†) $\odot$}

Studi Francesi è distribuita con Licenza Creative Commons Attribuzione - Non commerciale - Non opere derivate 4.0 Internazionale. 


\title{
Au corps du texte. Hommage à Georges Molinié. Sous la direction de Delphine Denis, Mireille Huchon, Anna Jaubert, Michael Rinn et Olivier Soutet
}

\author{
Monica Pavesio
}

\section{NOTIZIA}

Au corps du texte. Hommage à Georges Molinié. Sous la direction de Delphine DENIS, Mireille HUCHON, Anna JAUBERT, Michael RINN et Olivier SOUTET, Paris, Champion, 2010, pp. 551.

1 Il volume riunisce quaranta contributi che i colleghi e gli amici di Georges Molinié hanno voluto offrirgli come segno di stima. Questi studi sono suddivisi in tre sezioni, che rinviano agli interessi predominanti della riflessione letteraria dello studioso.

2 La prima sezione «Langages de la première modernité» rende omaggio al Molinié secentista. La sua importante tesi pubblicata nel 1982, Du Roman grec au roman baroque: un art majeur du genre narratif en France sous Louis XIII ( $2^{\circ}$ ed. PUM 1995), ha aperto piste feconde, sul piano metodologico, nello studio del romanzo secentesco.

In questa sezione segnaliamo i contributi di Jean-Michel ADAM, Le Petit Chaperon rouge de Perrault: conte d'effroi et fable sémiologique, pp. 17-30; di Wendy AYRES-BENNETT, «Exactitude $d u$ style»: les observations stylistiques chez les remarqueurs du XVII siècle, pp. 31-44; di Emmanuel BURY, Philologie et littérature: les enjeux esthétiques d'une pratique savante, de Balzac à Perrault, pp.45-57; di Daniela DALla VAlLE, La poétique de la tragicomédie, pp.59-70; di Jean-Charles DARMON, Politiques de l'analogie et régimes de l'exemplarité: remarques sur quelques gestes de Jean de La Fontaine, pp. 71-84; di Anne-Marie GARAGNON e 
Jean-Louis DE BoIsSIEU, Portraits d'animaux: rats et singes dans le Second Recueil des "Fables" de La Fontaine, pp. 85-97; di Robert GARRETTE, Iphigénie aux visages ou la poétique de la duplicité, pp. 99-110; di Sophie HACHE e Stéphane MACÉ, «Élevez maintenant, ô Seigneur! et mes pensées et ma voix» sur les énoncés exclamatifs dans les "Oraisons funèbres" de Bussuet, pp. 111-125; di John JACKSON, Le "cogito négatif» de La Princesse de Clèves, pp. 127-138; di Volker KAPP, Ingéniosité et style. Le débat italien sur le style au XVII siècle, pp. 139-149; di Dominique MAINGUENEAU, Commentaire et prédication. Le cas d'un sermon de Massillon, pp. 151-161; di Éric MÉcHoulan, Doxologie d'un duel et inactualité de l'art, pp. 163-173; di Fanny NÉPOTE-DESMARRES, Charles de Montchal, archevêque de Toulouse, pp.175-185; di Sylvianne RéMI-GIRAUD, Et si l'on prenait l'air de l'Académie..., pp.187-201; di Pierre RONZEAUD, La «pointe»: un langage textuel sur quelques usages pointus dans l'œuvre de Théophile de Viau, pp. 203- 216.

4 La seconda e la terza sezione, dedicate rispettivamente alla dimensione filologica e retorica del linguaggio e al discorso letterario, non contengono contributi sul xVII secolo. La tabula gratulatoria e la bibliografia delle opere di Georges Molinié concludono il volume. 